\title{
Plasma concentration of cis9trans11 CLA in males and females is influenced by SCD1 genetic variations and hormonal contraceptives: a cross-sectional study
}

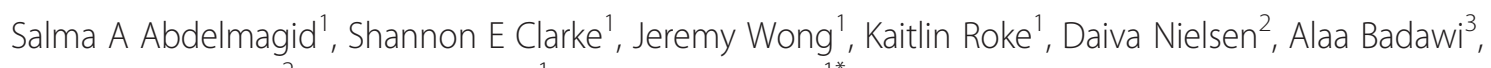
Ahmed El-Sohemy ${ }^{2}$, David M Mutch ${ }^{1}$ and David WL Ma ${ }^{1 *}$

\begin{abstract}
Background: The conjugated linoleic acid isomer cis9trans11 CLA can be endogenously synthesized from trans vaccenic acid (C18:1 t11) via desaturation at the delta 9 position catalyzed by the stearoyl-CoA desaturase 1 (SCD1), also known as delta-9 desaturase (D9D). Diet, hormonal regulation of gene expression and single nucleotide polymorphisms (SNPs) have been implicated in altering circulating levels of fatty acids. Hormonal contraceptives (HC) have also been shown to influence levels of some fatty acids. SNPs in SCD1 have been associated with altered levels of palmitoleic and oleic acids; however, associations between SCD1 SNPs and D9D desaturation index have not been previously examined in relation to CLA. Herein, we investigated the effects of sex and HC use on circulating concentrations of C9t11 CLA and D9D desaturation index. Furthermore, we determined the effects of ten SCD1 SNPs on D9D desaturation indices estimated by product to precursor ratio of C9t11 CLA to C18:1 t11.

Methods: Plasma samples were collected from subjects (Caucasian males: $n=113$; Caucasian females: $n=298$; Asian males: $\mathrm{n}=98$; Asian females: $\mathrm{n}=277$ ) from the Toronto Nutrigenomics and Health Study. Circulating fatty acids levels were measured by gas chromatography.
\end{abstract}

Results: Results show that circulating C9t11 CLA concentrations are significantly higher in females than males and they are further elevated in females using HC. In addition, a significant sex- and ethnic-specific association was found between SCD1 SNP rs10883463 ( $p=0.0014)$ and altered D9D activity in Caucasian males.

Conclusion: Findings from the present study identify SCD1 SNPs and hormonal contraceptives as factors altering endogenous C9t11 CLA levels in a sex- and ethnic-specific manner.

Keywords: C9t11 CLA, SCD1, Hormonal contraceptives, Single nucleotide polymorphisms

\section{Background}

Conjugated linoleic acids (CLA) are 18 carbon polyunsaturated fatty acids that are naturally found in ruminant meat and milk products. CLA isomers contain conjugated double bonds in different cis and trans configurations. CLA isomers include trans10cis12 CLA, cis11trans13 CLA and the most common isomer

\footnotetext{
* Correspondence: davidma@uoguelph.ca

'Department of Human Health and Nutritional Sciences, Animal Science/ Nutrition Building, Rm 342, College of Biological Science, University of Guelph, 491 Gordon Street, Guelph, Ontario, Canada

Full list of author information is available at the end of the article
}

cis9trans11 CLA (c9t11 CLA), also known as rumenic acid (RA) [1]. RA is the primary CLA isomer in ruminant and dairy products where it constitutes more than $80 \%$ of total CLA [2-4]. Considerable attention has been given to CLA as it has been shown to possess anticarcinogenic, anti-atherosclerotic and anti-inflammatory properties [5-13].

CLA is produced through biohydrogenation of polyunsaturated fatty acids by ruminant bacteria [14]. In addition, the CLA isomer c9t11 can also be derived through the delta-9-destaturation of the ruminant trans vaccenic acid (C18:1 t11). Trans vaccenic acid is the

\section{Biomed Central}

(c) 2013 Abdelmagid et al.; licensee BioMed Central Ltd. This is an Open Access article distributed under the terms of the Creative Commons Attribution License (http://creativecommons.org/licenses/by/2.0), which permits unrestricted use, distribution, and reproduction in any medium, provided the original work is properly cited. 
most abundant trans fatty acid (TFA) in ruminant meat and dairy products, although lesser amounts are also produced industrially $[3,15]$. Ruminant TFA are suggested to confer health benefits; however, more research is needed to substantiate their beneficial effects [16]. In a study conducted in male Hartley guinea pigs, animals fed ruminant TFA compared to animals fed industrial TFA had a smaller HDL particle profile; which has been associated with a lower risk of cardiovascular and heart disease [17]. Using a rodent model of metabolic syndrome, Wang et al. have shown trans vaccenic acid to have beneficial effects on lipids and lipoproteins [18]. Furthermore, trans vaccenic acid was shown to decrease the proinflammatory markers IL-2 and TNF- $\alpha[19,20]$.

In humans, trans vaccenic acid is converted to c9t11 CLA through a desaturation reaction catalyzed by stearoyl-CoA desaturase 1 (SCD1), also known as delta9 desaturase (D9D) [21-25]. SCD1 is a membrane-bound $40 \mathrm{kDa}$ protein localized to the endoplasmic reticulum [23]. It introduces a cis double bond in the delta 9 position of fatty acyl-CoA substrates, preferably palmitoylCoA (C16:0) and stearoyl-CoA (C18:0) to produce palmitoleoyl-CoA (C16:1) and oleoyl-CoA (C18:1), respectively. Changes in $S C D 1$ expression have been implicated in several diseases such as skin inflammation, pancreatic $\beta$-cell dysfunction, liver dysfunction and atherosclerosis [26]. Factors contributing to changes in SCD1 expression and SCD1 activity include hormonal regulation and single nucleotide polymorphisms (SNPs) $[27,28]$. Sex differences in $S C D 1$ expression were demonstrated in mice where females had higher levels of expression accompanied by higher levels of palmitoleic and oleic acids in the liver [29]. However, the underlying mechanistic basis for those differences is unknown. In humans, sex differences in SCD1 expression or levels of delta-9 desaturation product C9t11 CLA are not yet determined. Hormonal contraceptives (HC) have been shown to influence levels of the fatty acid docosahexaenoic acid which have also been shown to be present in significantly higher levels in females than in males [30]. Effect of $\mathrm{HC}$ use on the delta-9 desaturation index or C9t11 CLA levels is unknown.

SNPs in SCD1 have been associated with decreased body mass index (BMI), waist circumference and improved insulin sensitivity in elderly Swedish men [31]. Recently, SNPs in SCD1 have been shown to influence plasma levels of 16:0, 16:1, and 18:0, as well as Creactive protein, in individuals of European descent [28]; however, the effect of $S C D 1$ genetic variations on c9t11 CLA concentrations has not been previously examined. Consequently, it is unknown whether SCD1 genetic variants result in sex differences in circulating concentrations of c9t11 CLA. Therefore, the present study examined the influence of $S C D 1$ genetic variation and $\mathrm{HC}$ on circulating concentrations of C9t11 CLA in men and women in Canadian population of Caucasians and Asians.

\section{Methods}

\section{Study population}

Participants (Caucasians: males $=113$, females $=298$; Asians: males $=98$, females $=277$ ) were recruited as part of the Toronto Nutrigenomics and Health (TNH) Study [32] between September 2004 and July 2009. Ages of participants ranged between 20 and 29 years old and written informed consent was obtained from all of those who participated. Anthropometric measurements were recorded for all participants and health, life style, and food frequency questionnaires were completed by subjects. Total energy intake from fat and physical activity scores were calculated from completed questionnaires as previously described [32,33]. Following a $12 \mathrm{~h}$ fast, plasma samples were collected for measurement of biomarkers of glucose and lipid metabolism. HOMA-IR was calculated using the homeostasis model assessment method [34]. Women who were pregnant or breastfeeding were not included in the study. No other exclusion criteria were included in these analyses. The study protocol was approved by the Research Ethics Boards at the University of Toronto and University of Guelph.

\section{Gas chromatography analysis}

Subjects were required to fast overnight for a minimum of $12 \mathrm{~h}$ prior to blood collection and separation of plasma. Samples were frozen and stored at $-80^{\circ} \mathrm{C}$. Frozen plasma samples were thawed on ice for $30 \mathrm{~min}$ and a mixture of chloroform: methanol $(2: 1 \mathrm{v} / \mathrm{v})$ was added to a $50 \mu \mathrm{l}$ aliquot as described previously [35]. Free fatty acid C17:0 was used as an internal standard $(5 \mu \mathrm{g}$ of $1 \mathrm{mg} / \mathrm{ml}$ stock). Samples were flushed with nitrogen gas prior to storage over night at $4^{\circ} \mathrm{C}$. The next day, samples were subjected to a double extraction, saponification, methylation and quantification of fatty acid methyl esters, as previously described [36]. Fatty acid methyl esters were separated by gas chromatography using an Agilent7890A gas chromatograph (Agilent Technologies, Palto, Alto, Ca) with a Supelco SP 2560 fused-silics capillary column $(100 \mathrm{~m} \times 0.25 \mathrm{~mm}$ i.d., $0.2 \mu \mathrm{m}$ film thickness; Sigma-Aldrich, St-Louis, MO). The carrier gas, Hydrogen, was set at a constant flow rate of $30 \mathrm{~mL} /$ min. Samples were injected in splitless mode. Both injector and detector ports were set at $250^{\circ} \mathrm{C}$. Fatty acid methyl esters were eluted through the column using temperature program of: $0.2 \mathrm{~min}$ at $60^{\circ} \mathrm{C}$, then increasing $13^{\circ} \mathrm{C} / \mathrm{min}$ until a temperature of $170^{\circ} \mathrm{C}$ was reached. After $4 \mathrm{~min}$ at $170^{\circ} \mathrm{C}$, the temperature: increased $6.5^{\circ} \mathrm{C} /$ min to $175^{\circ} \mathrm{C}$, increased $2.6^{\circ} \mathrm{C} / \mathrm{min}$ to $185^{\circ} \mathrm{C}$, increased $1.3^{\circ} \mathrm{C} / \mathrm{min}$ to $190^{\circ} \mathrm{C}$, and finally increased $13^{\circ} \mathrm{C} / \mathrm{min}$ to $240^{\circ} \mathrm{C}$ and held at $240^{\circ} \mathrm{C}$ for $13 \mathrm{~min}$. The processing 
time per sample was $37.77 \mathrm{~min}$. Peak retention times of a known internal standard (Nu-Chek-Prep, Elysian, $\mathrm{MN}$ ) were used to identify fatty acids. Fatty acid peak areas were determined using EZChrom Elite software (Version 3.3.2) [37]. The internal standard was used to calculate fatty acid concentrations $(\mu \mathrm{g} / \mathrm{ml})$. An estimate of delta9-desaturase (D9D) desaturation index was calculated by dividing concentrations of product (18:2c9t11 CLA) by precursor (18:1 t11) as previously described [36].

\section{Genotyping}

Identification of SCD1 SNPs, selection of SNPs, and genotyping was performed as previously described by Stryjecki et al. [28].

\section{Statistical analysis of data}

Results are expressed as mean \pm standard error mean. All data was analyzed using JMP genomics software V5 (SAS Institute, Cary, NC), which was also used to test Hardy-Weinberg equilibrium for each genotype. A student's t-test was used to determine differences in fatty acid concentrations and ratios between males and females. A Tukey's HSD post-hoc test was used to determine differences in desaturase indices for each genotype. P-values of analyses of fatty acid levels or desaturase indices were determined using linear regression models which were adjusted for BMI, age, total energy intake from dietary fat and physical activity. Linear regression models were used to identify associations between individual SNPs, desaturase indices and use of hormonal contraceptives and were adjusted for BMI, age, \% of Total Energy from Dietary Fat and physical activity. A p-value of $<0.05$ was considered statistically significant.

\section{Results}

Study population

General characteristics of subjects used in the study are presented in Table 1.

\section{Gender influences plasma concentrations of 18:2c9t11 and D9D index}

Plasma concentrations of fatty acids are presented in Table 2. There was no significant difference in 18:1 t11 concentrations between Caucasian males and females; however, Asian females had significantly higher concentrations of 18:1 t11 compared to Asian males ( $\mathrm{p}=0.04)$. Both Caucasian and Asian females had significantly higher concentrations of 18:2c9t11 and D9D indices compared to males within the same ethnicity $(\mathrm{p}<0.01)$.

\section{Association of hormonal contraceptive (HC) use and altered fatty acid concentrations}

Plasma concentrations of fatty acids in females using hormonal contraceptives $(\mathrm{HC})$ compared to females not using contraceptives are presented in Table 3. In Caucasians, females using $\mathrm{HC}$ had significantly higher concentrations of $18: 1 \mathrm{t} 11$ and $18: 2 \mathrm{c} 9 \mathrm{t} 11$ than Caucasian females who were not users $(\mathrm{p}=0.0037, \mathrm{p}<0.0001$, respectively). In Asians, there was no significant difference in 18:1 t11 concentrations between users and non-users; however, females using $\mathrm{HC}$ had significantly higher concentrations of 18:2c9t11 ( $\mathrm{p}<0.0001)$. In both Caucasians and Asians, [18:2c9t11/18:1 t11] desaturase indices tended to be higher in females using $\mathrm{HC}(\mathrm{p}=0.0581$ and $\mathrm{p}=0.0503$, respectively) than in females not using contraceptives (Table 3).

Table 1 General characteristics of study population at fasting state compared by sex and separated by ethnicity

\begin{tabular}{|c|c|c|c|c|c|c|}
\hline & \multicolumn{3}{|c|}{ Caucasians } & \multicolumn{3}{|c|}{ Asians } \\
\hline & Males & Females & P-value & Males & Females & P-value \\
\hline Population (\#) & 113 & 298 & & 98 & 277 & \\
\hline Hormonal contraceptive users (\%) & $\mathrm{N} / \mathrm{A}$ & 46.0 & & $\mathrm{~N} / \mathrm{A}$ & 15.5 & \\
\hline Age (yrs) & $23.1 \pm 0.2$ & $23.1 \pm 0.1$ & 0.87 & $22.4 \pm 0.2$ & $22.1 \pm 0.1$ & 0.26 \\
\hline BMI $\left(\mathrm{kg} / \mathrm{m}^{2}\right)$ & $23.3 \pm 0.3$ & $23.1 \pm 0.2$ & 0.54 & $23.2 \pm 0.3$ & $21.2 \pm 0.1$ & $<0.01^{*}$ \\
\hline HOMA-IR & $1.16 \pm 0.08$ & $1.39 \pm 0.05$ & $0.02^{*}$ & $1.42 \pm 0.08$ & $1.45 \pm 0.10$ & 0.84 \\
\hline Glucose (mmol/L) & $4.88 \pm 0.07$ & $4.70 \pm 0.02$ & $<0.01^{*}$ & $4.95 \pm 0.04$ & $4.73 \pm 0.02$ & $<0.01^{*}$ \\
\hline Insulin (pmol/L) & $37.1 \pm 2.1$ & $47.4 \pm 1.7$ & $<0.01^{*}$ & $45.7 \pm 2.3$ & $48.1 \pm 2.9$ & 0.62 \\
\hline Total cholesterol (mmol/L) & $3.97 \pm 0.07$ & $4.35 \pm 0.05$ & $<0.01^{*}$ & $4.13 \pm 0.08$ & $4.29 \pm 0.04$ & $<0.05^{*}$ \\
\hline HDL-cholesterol (mmol/L) & $1.38 \pm 0.03$ & $1.69 \pm 0.02$ & $<0.01^{*}$ & $1.39 \pm 0.03$ & $1.68 \pm 0.02$ & $<0.01^{*}$ \\
\hline LDL-cholesterol (mmol/L) & $2.16 \pm 0.06$ & $2.23 \pm 0.04$ & 0.32 & $2.29 \pm 0.07$ & $2.21 \pm 0.04$ & 0.24 \\
\hline Triglycerides (mmol/L) & $0.96 \pm 0.05$ & $0.97 \pm 0.02$ & 0.86 & $0.98 \pm 0.05$ & $0.91 \pm 0.02$ & 0.19 \\
\hline Free fatty acids (mmol/L) & $454 \pm 24.6$ & $489 \pm 14.2$ & 0.21 & $453 \pm 21.4$ & $521 \pm 15.4$ & $0.02^{*}$ \\
\hline$\%$ of Total Energy from Dietary Fat & $27.4 \pm 0.6$ & $27.9 \pm 0.4$ & 0.56 & $26.3 \pm 0.5$ & $26.2 \pm 0.3$ & 0.98 \\
\hline
\end{tabular}

Statistical differences were determined using a Student's T-test. The ${ }^{*}$ denotes $p$-values which are significant $(<0.05)$. 
Table 2 Estimates of fatty acid concentrations $(\mu \mathrm{g} / \mathrm{ml})$ in Caucasian and Asian males and females

\begin{tabular}{|c|c|c|c|c|c|c|}
\hline \multirow[t]{2}{*}{ Fatty acids } & \multicolumn{3}{|c|}{ Caucasians } & \multicolumn{3}{|c|}{ Asians } \\
\hline & Males & Females & P-value & Males & Females & P-value \\
\hline 18:0 & $131.9 \pm 3.3$ & $137.7 \pm 1.8$ & 0.08 & $133.1 \pm 3.0$ & $140.1 \pm 1.8$ & $0.03^{*}$ \\
\hline $18: 1$ t9 & $4.1 \pm 0.2$ & $4.7 \pm 0.2$ & $0.04^{*}$ & $3.7 \pm 0.2$ & $4.4 \pm 0.2$ & $<0.01^{*}$ \\
\hline 18:1 t11 & $4.6 \pm 0.2$ & $4.8 \pm 0.2$ & 0.50 & $4.0 \pm 0.2$ & $4.3 \pm 0.2$ & $0.04^{*}$ \\
\hline 18:2c9t11 & $4.5 \pm 0.2$ & $5.3 \pm 0.1$ & $<0.01^{*}$ & $3.7 \pm 0.1$ & $4.1 \pm 0.1$ & $<0.01^{*}$ \\
\hline $18: 2 \mathrm{c} 11 \mathrm{t} 13$ & $0.5 \pm 0.0$ & $0.6 \pm 0.0$ & 0.15 & $0.5 \pm 0.1$ & $0.5 \pm 0.0$ & $<0.01^{*}$ \\
\hline $18: 2 \mathrm{t} 10 \mathrm{c} 12$ & $1.1 \pm 0.1$ & $1.2 \pm 0.0$ & 0.16 & $1.2 \pm 0.1$ & $1.2 \pm 0.0$ & 0.73 \\
\hline 18:2c9t11/18:1 t11 & $1.0 \pm 0.0$ & $1.2 \pm 0.0$ & $<0.01^{*}$ & $1.1 \pm 0.0$ & $1.1 \pm 0.0$ & $0.01^{*}$ \\
\hline
\end{tabular}

Select fatty acids used as substrate and product of D9D, desaturase index and major CLA isomers are reported. The * denotes p-values which are significant $(<0.05)$. P-values were determined using linear regression models which were adjusted for BMl, age, \% of Total Energy from Dietary Fat and physical activity Caucasian Males: $n=113$; Caucasian females: $n=298$; Asian Males: $n=98$; Asian Females: $n=277$.

\section{SNP selection}

The 10 selected SNPs from the SCD1 gene were in HWE in Caucasian males and females as well as in the Asian females (Table 4). SCD1 SNP: rs575338 was not polymorphic $(\mathrm{MAF}=0)$ in Asian males and, therefore, was excluded from further analyses in this subgroup of subjects (Table 4).

\section{Association of SCD1 SNPs and [18:2c9t11/18:1 t11] desaturase indices}

Regression analysis of ten SCD1 SNPS and D9D indices [18:2c9t11/18:1 t11] revealed no significant associations in Caucasian females, Asian males, or Asian females (Tables 5 and 6). However, in Caucasian males rs10883463 was significantly associated with altered D9D desaturation index $(\mathrm{p}<0.01)$. In this population, carriers of the minor C allele (19 out of 113 Caucasian males) had significantly lower D9D desaturase indices compared to homozygote carriers of the common $\mathrm{T}$ allele (Table 5). Further analysis to determine associations between rs10883463 and other D9D desaturation indices $([18: 1 / 18]$ and [16:1/16]) revealed no significant associations (data not shown). Thus, the association identified between rs10883463 and [18:2c9t11/18:1 t11] desaturase index potentially reveals a substrate specific association between this SNP and D9D enzymatic activity; however, this association was lost when we adjusted for multiple testing.

\section{Discussion}

Circulating levels of c9t11 CLA may be potentially influenced by a number of factors including differences in dietary intake [38,39], differential expression of SCD1, or genetic variations in SCD1 leading to differential enzymatic activity. The latter two factors have not been previously examined and are the focus of the present study where we show sex-specific modulation of circulating CLA.

Firstly, plasma concentrations of c9t11 CLA in two major ethnicities and both sexes were quantified on an absolute basis. These results revealed significant differences in circulating plasma concentrations of c9t11 CLA between males and females in both ethnicities. Females had significantly higher circulating c9t11 concentrations than their male counterparts $(\mathrm{p}<0.01)$. Previously, Zlatanos et al. reported plasma CLA levels in humans but as percent of total fatty acids and although both males and females were included in the study,

Table 3 Estimates of fatty acid concentrations $(\mu \mathrm{g} / \mathrm{ml})$ in Caucasian and Asian females using hormonal contraceptives

\begin{tabular}{|c|c|c|c|c|c|c|}
\hline \multirow[t]{2}{*}{ Fatty acids } & \multicolumn{3}{|c|}{ Caucasians } & \multicolumn{3}{|c|}{ Asians } \\
\hline & non $(n=161)$ & $H C(n=137)$ & P-value & non $(n=234)$ & $\mathrm{HC}(n=43)$ & P-value \\
\hline 18:0 & $134.7 \pm 2.5$ & $141.3 \pm 2.5$ & 0.03 & $139.4 \pm 2.0$ & $143.6 \pm 4.2$ & 0.20 \\
\hline $18: 1$ t9 & $4.2 \pm 0.2$ & $5.2 \pm 0.3$ & $<0.01^{*}$ & $4.2 \pm 0.2$ & $5.5 \pm 0.5$ & $0.02^{*}$ \\
\hline 18:1 t11 & $4.4 \pm 0.2$ & $5.3 \pm 0.3$ & $<0.01^{*}$ & $4.2 \pm 0.2$ & $5.0 \pm 0.4$ & 0.13 \\
\hline $18: 2 c 9 t 11$ & $4.5 \pm 0.1$ & $6.1 \pm 0.2$ & $<0.01^{*}$ & $3.9 \pm 0.1$ & $5.2 \pm 0.3$ & $<0.01^{*}$ \\
\hline $18: 2 \mathrm{c} 11 \mathrm{t} 13$ & $0.6 \pm 0.0$ & $0.6 \pm 0.0$ & 0.07 & $0.5 \pm 0.0$ & $0.7 \pm 0.1$ & $<0.01^{*}$ \\
\hline $18: 2 \mathrm{t} 10 \mathrm{c} 12$ & $1.1 \pm 0.1$ & $1.2 \pm 0.0$ & 0.12 & $1.2 \pm 0.0$ & $1.3 \pm 0.1$ & 0.26 \\
\hline 18:2c9t11/18:1 t11 & $1.2 \pm 0.1$ & $1.3 \pm 0.0$ & 0.06 & $1.1 \pm 0.0$ & $1.2 \pm 0.1$ & 0.05 \\
\hline
\end{tabular}

Select fatty acids used as substrate and product of D9D, desaturase index and major CLA isomers are reported. *denotes p-values which are significant (< 0.05). P-values were determined using linear regression models which were adjusted for BMI, age, \% of Total Energy from Dietary Fat and physical activity. Abbreviations: HC, females using hormonal contraceptives; non, females that are not using hormonal contraceptives. 
Table 4 HWE values of SCD1 and their genotype frequencies

\begin{tabular}{|c|c|c|c|c|c|c|c|c|c|c|c|c|}
\hline \multirow[t]{3}{*}{ SNP } & \multicolumn{6}{|c|}{ Caucasians } & \multicolumn{6}{|c|}{ Asians } \\
\hline & \multicolumn{3}{|c|}{ Males } & \multicolumn{3}{|c|}{ Females } & \multicolumn{3}{|c|}{ Males } & \multicolumn{3}{|c|}{ Females } \\
\hline & HWE & Major allele & MAF & HWE & Major allele & MAF & HWE & Major allele & MAF & HWE & Major allele & MAF \\
\hline rs10883463 & 0.79 & $T$ & 0.09 & 0.99 & $T$ & 0.10 & 0.99 & $T$ & 0.01 & 0.98 & $T$ & $1.9 \cdot 10^{-3}$ \\
\hline rs417669878 & 0.79 & G & 0.42 & 0.99 & G & 0.42 & 0.98 & G & 0.26 & 0.98 & G & 0.28 \\
\hline rs2060792 & 0.83 & A & 0.26 & 0.99 & A & 0.29 & 0.99 & A & 0.39 & 0.98 & A & 0.31 \\
\hline rs3071 & 0.79 & $\mathrm{~T}$ & 0.29 & 0.99 & $\mathrm{~T}$ & 0.31 & 0.98 & T & 0.27 & 0.98 & $T$ & 0.28 \\
\hline rs3793766 & 0.79 & C & 0.12 & 0.99 & C & 0.08 & 0.99 & C & 0.17 & 0.98 & C & 0.18 \\
\hline rs3793767 & 0.82 & $\mathrm{~T}$ & 0.40 & 0.99 & $\mathrm{~T}$ & 0.37 & 0.98 & $\mathrm{~T}$ & 0.45 & 0.98 & $\mathrm{~T}$ & 0.35 \\
\hline rs490726 & 0.67 & T & 0.22 & 0.99 & $\mathrm{~T}$ & 0.19 & 0.99 & $\mathrm{~T}$ & 0.23 & 0.98 & T & 0.28 \\
\hline rs522951 & 0.83 & G & 0.48 & 0.99 & G & 0.49 & 0.99 & G & 0.42 & 0.98 & G & 0.32 \\
\hline rs569184 & 0.79 & C & 0.12 & 0.99 & C & 0.08 & 0.99 & C & 0.20 & 0.98 & C & 0.28 \\
\hline rs575338 & 0.79 & G & 0.15 & 0.99 & G & 0.13 & NP & G & & 0.98 & G & $5.6 \cdot 10^{-3}$ \\
\hline
\end{tabular}

SNPs with HWE p-values less than 0.05 are not in Hardy-Weinberg Equilibrium. Caucasian Males: $n=113 ;$ Caucasian females: $n=298 ;$ Asian Males: $n=98$; Asian Females: $\mathrm{n}=277$. Abbreviations: HWE, Hardy-Weinberg Equilibrium p-values; $M A F$, minor allele frequency; $N P$, not polymorphic $(M A F=0)$.

comparison of CLA levels between sexes was not performed [39]. In the present study plasma concentrations of fatty acids were determined because they provide a quantitative perspective on the pool size as compared to relative percent composition, which is influenced by the abundance of other fatty acids. Others have determined plasma concentrations of CLA in dietary intervention studies $[38,40,41]$ which fall within the same range found in this study $(0.5-40 \mu \mathrm{mol} / \mathrm{L})$. Herbel et al. included both males and females in their study of the effects of sunflower consumption on circulating CLA concentrations [40]; however, comparison of circulating C9t11 CLA concentrations between males and females or different ethnicities was not performed. We recognize that differences in CLA concentrations, determined in this study, between males and females may be viewed as small. Whether these apparent small changes are relevant to health will require further human studies. Nonetheless, these data contribute to our fundamental knowledge of baseline levels of CLA, and factors influencing these levels, which will be necessary for such studies. Our study participants were not consuming a standardized diet; however, values for energy intake from fat (i.e. \% of Total Energy from Dietary Fat) were calculated with food frequency questionnaires and included as a covariate in our linear regression models in order to account for potential differences in fat intake. It is plausible that diet contributes to circulating c9t11 CLA concentrations in a sex-specific manner; however, according to a recent study by Nikpartow et al., Canadian females have lower milk consumption than Canadian males [42]. And in an overview of Canadian eating habits, males

Table 5 Estimates of D9D activity according to genotype for each SCD1 SNP in Caucasians

\begin{tabular}{|c|c|c|c|c|c|c|c|c|}
\hline & \multicolumn{4}{|c|}{ [18:2c9t11/18:1 t11] in males } & \multicolumn{4}{|c|}{ [18:2c9t11/18:1 t11] in females } \\
\hline & MM & $\mathrm{Mm}$ & $\mathrm{mm}$ & P-value & MM & $\mathrm{Mm}$ & $\mathrm{mm}$ & P-value \\
\hline rs10883463 & $1.077 \pm 0.036^{a}$ & $0.769 \pm 0.048^{b}$ & - & $<0.01^{*}$ & $1.206 \pm 0.036$ & $1.244 \pm 0.061$ & $1.505 \pm 0.170$ & 0.75 \\
\hline rs17669878 & $1.079 \pm 0.070$ & $0.977 \pm 0.040$ & $1.064 \pm 0.076$ & 0.23 & $1.248 \pm 0.041$ & $1.195 \pm 0.050$ & $1.207 \pm 0.074$ & 0.72 \\
\hline rs2060792 & $1.015 \pm 0.037$ & $0.998 \pm 0.061$ & $1.215 \pm 0.179$ & 0.62 & $1.251 \pm 0.053$ & $1.175 \pm 0.036$ & $1.229 \pm 0.088$ & 0.58 \\
\hline rs3071 & $1.037 \pm 0.052$ & $1.024 \pm 0.046$ & $0.913 \pm 0.051$ & 0.78 & $1.202 \pm 0.031$ & $1.224 \pm 0.059$ & $1.238 \pm 0.105$ & 0.87 \\
\hline rs3793766 & $1.003 \pm 0.036$ & $1.083 \pm 0.078$ & 1.200 & 0.59 & $1.217 \pm 0.035$ & $1.209 \pm 0.057$ & $1.084 \pm 0.391$ & 0.94 \\
\hline rs3793767 & $0.939 \pm 0.042$ & $1.043 \pm 0.051$ & $1.111 \pm 0.097$ & 0.25 & $1.178 \pm 0.043$ & $1.252 \pm 0.052$ & $1.200 \pm 0.054$ & 0.81 \\
\hline rs490726 & $1.073 \pm 0.042$ & $0.960 \pm 0.053$ & $0.856 \pm 0.344$ & 0.23 & $1.215 \pm 0.041$ & $1.217 \pm 0.046$ & $1.229 \pm 0.107$ & 0.99 \\
\hline rs522951 & $1.044 \pm 0.046$ & $1.011 \pm 0.050$ & $1.019 \pm 0.081$ & 0.78 & $1.125 \pm 0.055$ & $1.252 \pm 0.049$ & $1.237 \pm 0.048$ & 0.42 \\
\hline rs569184 & $1.010 \pm 0.036$ & $1.060 \pm 0.079$ & 1.200 & 0.72 & $1.223 \pm 0.035$ & $1.198 \pm 0.054$ & $0.637 \pm 0.055$ & 0.38 \\
\hline rs575338 & $1.024 \pm 0.042$ & $1.024 \pm 0.045$ & $1.003 \pm 0.155$ & 0.99 & $1.193 \pm 0.029$ & $1.291 \pm 0.098$ & $1.188 \pm 0.084$ & 0.44 \\
\hline
\end{tabular}

Results of analysis of 10 SNPs from SCD1 for associations with D9D activity index [182c9t11:181 t11]. Different letters (a or b) denote values that are significantly different between groups. P-values were determined using linear regression models which were adjusted for BMI, age, \% of Total Energy from Dietary Fat and physical activity. Caucasian Males: $\mathrm{n}=113$; Caucasian females: $\mathrm{n}=298$; Asian Males: $\mathrm{n}=98$; Asian Females: $\mathrm{n}=277$. Abbreviations: $D 9 D$, delat-9-desaturase; $M$, major; $\mathrm{m}$, minor; ' - ' indicates that no subjects with this genotype were present in this population. 
Table 6 Estimates of D9D activity according to genotype for each SCD1 SNP in Asians

\begin{tabular}{|c|c|c|c|c|c|c|c|c|}
\hline & \multicolumn{4}{|c|}{ [18:2c9t11/18:1 t11] in males } & \multicolumn{4}{|c|}{ [18:2c9t11/18:1 t11] in females } \\
\hline & MM & $\mathrm{Mm}$ & $\mathrm{mm}$ & P-value & MM & $\mathrm{Mm}$ & $\mathrm{mm}$ & P-value \\
\hline rs10883463 & $1.039 \pm 0.041$ & $0.813 \pm 0.064$ & - & 0.46 & $1.085 \pm 0.027$ & 0.783 & - & 0.23 \\
\hline rs17669878 & $1.094 \pm 0.059$ & $0.966 \pm 0.052$ & $0.910 \pm 0.118$ & 0.18 & $1.035 \pm 0.035$ & $1.139 \pm 0.043$ & $1.061 \pm 0.096$ & 0.28 \\
\hline rs2060792 & $0.949 \pm 0.049$ & $1.052 \pm 0.064$ & $1.185 \pm 0.107$ & 0.27 & $1.090 \pm 0.040$ & $1.058 \pm 0.038$ & $1.185 \pm 0.084$ & 0.37 \\
\hline rs3071 & $1.069 \pm 0.061$ & $0.959 \pm 0.048$ & $1.103 \pm 0.121$ & 0.34 & $1.052 \pm 0.038$ & $1.143 \pm 0.041$ & $0.939 \pm 0.063$ & 0.11 \\
\hline rs3793766 & $1.035 \pm 0.047$ & $1.053 \pm 0.081$ & $0.752 \pm 0.036$ & 0.88 & $1.072 \pm 0.030$ & $1.117 \pm 0.056$ & $0.906 \pm 0.081$ & 0.59 \\
\hline rs3793767 & $0.993 \pm 0.057$ & $1.028 \pm 0.058$ & $1.120 \pm 0.104$ & 0.66 & $1.109 \pm 0.044$ & $1.051 \pm 0.037$ & $1.120 \pm 0.067$ & 0.54 \\
\hline rs490726 & $1.035 \pm 0.048$ & $1.070 \pm 0.077$ & $0.795 \pm 0.051$ & 0.68 & $1.056 \pm 0.034$ & $1.128 \pm 0.044$ & $1.038 \pm 0.101$ & 0.19 \\
\hline rs522951 & $0.975 \pm 0.053$ & $1.030 \pm 0.062$ & $1.164 \pm 0.102$ & 0.40 & $1.095 \pm 0.041$ & $1.058 \pm 0.038$ & $1.156 \pm 0.080$ & 0.42 \\
\hline rs569184 & $1.041 \pm 0.049$ & $1.052 \pm 0.076$ & $0.807 \pm 0.064$ & 0.86 & $1.045 \pm 0.034$ & $1.129 \pm 0.046$ & $1.070 \pm 0.093$ & 0.25 \\
\hline rs575338 & $\mathrm{N} / \mathrm{A}$ & & & & $1.082 \pm 0.027$ & $0.815 \pm 0.143$ & - & 0.47 \\
\hline
\end{tabular}

Results of analysis of 10 SNPs from SCD1 for associations with D9D activity index [182c9t11:181 t11]. P-values were determined using linear regression models which were adjusted for BMI, age, \% of Total Energy from Dietary Fat and physical activity. Caucasian Males: $n=113 ;$ Caucasian females: $n=298 ;$ Asian Males: $\mathrm{n}=98$; Asian Females: $\mathrm{n}=277$. Abbreviations: $D 9 D$, delat-9-desaturase; $M$, major; $m$, minor; $n a$, not applicable; ' ${ }^{\prime}$ indicates that no subjects with this genotype were present in this population.

were reported to consume more meat than females [43]. Thus, the significantly higher levels of CLA in females compared to males observed in this study has a low likelihood to be a result of differences in dietary intake of CLA.

In addition to diet, differential gene expression of SCD1 can contribute to the differences observed in c9t11 CLA concentrations between males and females. Several hormones have been shown to affect SCD1 expression [44]; thus, they could also contribute to sex differences. In that regard, further stratification of female population by $\mathrm{HC}$ use revealed that female users of $\mathrm{HC}$ had significantly higher circulating c9t11 CLA concentrations than females who were non-users in both Caucasian and Asian populations. Recently, an examination of the effect of $\mathrm{HC}$ use on proteomic biomarkers in plasma of TNH study participants revealed that while use of $\mathrm{HC}$ had a significant effect on alteration of proteomic biomarkers, the type of $\mathrm{HC}$ used and duration of use had no apparent effect. Thus, further stratification of our analysis according to type of HC used or duration of use was not performed in this study [45]. Plasma concentrations of c9t11CLA and 18:1 t11 were used to estimate D9D desaturation index. Although there was a trend towards greater [18:2c9t11/18:1 t11] desaturase indices in females using $\mathrm{HC}$ from both ethnicities, use of $\mathrm{HC}$ was not significantly associated with altered D9D desaturase index (Table 3). Several hormones have been shown to modulate $S C D 1$ expression. For instance, insulin has been shown to have a positive effect on SCD1 transcription, while leptin and estrogen were shown to act as inhibitors [44]. Although estrogen is an inhibitor of SCD1 expression, the effect of estrogen or hormonal contraceptives on circulating c9t11 CLA concentrations have not been previously reported. HC have been shown to increase levels of the polyunsaturated fatty acid docosahexaenoic acid in females using contraceptives compared to females that were not [30]. The positive association between $\mathrm{HC}$ and c9t11 CLA levels observed in this study warrants further research to elucidate the mechanism by which $\mathrm{HC}$ can increase circulating levels of c9t11 CLA. Future research by our laboratory will also investigate the effect of $\mathrm{HC}$ use on other D9D products such as 18:1n9 and 16:1n7.

To the best of our knowledge, association between SCD1 SNPs and D9D activity, estimated by [18:2c9t11/ 18:1 t11] desaturase index, has not been previously reported. To determine whether SCD1 SNPs contributed to the different levels of c9t11 CLA or to differences in D9D deasturase index between sexes, linear regression analyses were performed. Results revealed that rs10883463 was significantly $(\mathrm{p}=0.0014)$ associated with altered D9D desaturation index in Caucasian males (Table 5). Of the Caucasian male participants in our study cohort, $17 \%$ had the genotype associated with decreased D9D desaturation index; however, linear regression models revealed no significant association between D9D indices and SCD1 SNPs in the 3 additional populations tested (Caucasian females, Asian males and Asian females). The lack of additional associations between rs10883463 and other D9D indices (16:1/16:0 and 18:1/18:0) within the Caucasian male population led us to conclude that the association identified between this SNP and CLA may suggest a degree of specificity for 18:1 t11; however, this requires confirmation in other populations in order to substantiate this hypothesis. Furthermore, we acknowledge that this association was not significant following an adjustment for multiple testing, further reinforcing the need for independent verification. Nevertheless, in a recent study of variations of SCD1 and associations with relative levels of palmitic and 
stearic acids in Caucasian and Asian subjects, Stryjecki et al. identified a significant association between SCD1 SNP rs2060792 and lower palmitic acid but higher stearic acid levels in Caucasian women only; however, associations with [16:1/16:0] and [18:1/18:0] desaturase indices were not significant [28]. Our work in the present study, which has used a much larger cohort, supports this lack of association. The D9D activity is highest for 18:1/18:0, intermediate for $\mathrm{c} 9 \mathrm{t} 11 / \mathrm{t} 11$ and lowest for 16:1/16:0. While there is emerging evidence that $S C D 1$ polymorphisms are associated with either the precursor, product or desaturase indices of relevant fatty acids, there remains a need for direct evidence to establish these potential cause-effect relationships. Further validation is required to demonstrate the direct relationship between the SNP identified in this study (rs10883463) and SCD1 biochemistry.

In this study we acknowledge the limitation of using plasma as a source for fatty acid measurements, which typically reflects a combination of recent dietary intake and hepatic synthesis; however, since subjects fasted overnight prior to blood collection the contribution of dietary fat to the blood fatty acid profile is expected to be negligible. Although red blood cells or adipose tissue might be argued to better reflect long term status, Baylin et al. found that fasting plasma fatty acids correlated with fatty acids in adipose tissue [46]. However, there remains a need for more extensive studies to determine whether plasma, red blood cells, adipose tissue or other tissues are most suited for correlation analysis with $S C D 1$ polymorphisms. Another limitation to the present study was that food frequency questionnaire data for CLA did not correlate with plasma CLA values (data not shown), suggesting that the FFQ used in the present study may lack sensitivity with regards to estimating dietary CLA intake. Therefore we cannot fully negate the contribution of diet to plasma fatty acid levels. Future studies require careful measurement of CLA from multiple blood fractions in tandem with more extensive and detailed recording of dietary CLA intake. Nonetheless, results from this study provide fundamental knowledge regarding determinants of circulating CLA levels. Data demonstrate a minor role for genetic variation in $S C D 1$ in determining circulating CLA levels in different ethnicities or sexes and a significant role for hormonal contraceptive use in altering circulating CLA levels in females. These findings can be utilized in future clinical and nutritional studies when it is essential to understand factors that may have a significant influence on baseline levels of CLA (i.e. hormonal contraceptive use) versus factors that may have only a minor influence on CLA variation (i.e. genetic polymorphisms in SCD1).

\section{Conclusion}

Overall, this study demonstrates that sex, $\mathrm{HC}$ use and SCD1 polymorphisms can influence c9t11 CLA concentrations. The implications of CLA in chronic diseases such as obesity, inflammation, cardiovascular disease and cancer [47] necessitate better understanding of the diverse factors influencing circulating concentrations of this fatty acid as well as their sex- and ethnic-specific effects.

\section{Abbreviations}

BMI: Body mass index; CLA: Conjugated linoleic acid; D9D: Delta-9 desaturase; HC: Hormonal contraceptives; HWE: Hardy-Weinberg equilibrium; MAF: Minor allele frequency; RA: Rumenic acid; SCD1: Stearoyl-CoA desaturase 1; SNP: Single nucleotide polymorphism; TFA: Trans fatty acid.

\section{Competing interest}

The authors declare that they have no competing interests.

\section{Authors' contributions}

SA performed data analysis, interpreted results, assisted with gas chromatography and drafted the manuscript. SC carried out gas chromatography analyses and critically revised manuscript. JW assisted in data analysis. KR carried out genotyping studies. DN collected DNA samples from all participants. $A B, A E$ and $D M M$ assisted in interpretation of results and critically revised manuscript. DWLM conceived and designed study, assisted in interpretation of data and critically revised manuscript. All authors read and approved the final manuscript.

\section{Acknowledgements}

This research was funded by grants from the Advanced Food and Materials Network (DMM and AE-S), the Public Health Agency of Canada (DMM and $A B)$, and the Canada Foundation for Innovation with matching funds from the Ontario Research Fund (DWLM and DMM) and Natural Sciences and Engineering Research Council of Canada (DWLM). The authors would like to thank Lyn Hillyer for technical support.

\section{Author details}

'Department of Human Health and Nutritional Sciences, Animal Science/ Nutrition Building, Rm 342, College of Biological Science, University of Guelph, 491 Gordon Street, Guelph, Ontario, Canada. ${ }^{2}$ Department of Nutritional Sciences, University of Toronto, Toronto, Ontario, Canada. ${ }^{3}$ Office for Biotechnology, Genomics and Population Health, Public Health Agency of Canada, Toronto, Ontario, Canada.

Received: 26 February 2013 Accepted: 16 July 2013

Published: 18 July 2013

\section{References}

1. Kepler CR, Hirons KP, McNeill JJ, Tove SB: Intermediates and products of the biohydrogenation of linoleic acid by Butyrinvibrio fibrisolvens. J Biol Chem 1966, 241:1350-1354.

2. Kraft J, Hanske L, Mockel P, Zimmermann S, Hartl A, Kramer JK, et al: The conversion efficiency of trans-11 and trans-12 18:1 by Delta9-desaturation differs in rats. J Nutr 2006, 136:1209-1214.

3. Mendis S, Cruz-Hernandez C, Ratnayake WM: Fatty acid profile of Canadian dairy products with special attention to the trans-octadecenoic acid and conjugated linoleic acid isomers. J AOAC Int 2008, 91:811-819.

4. Ma DW, Wierzbicki AA, Field CJ, Clandinin MT: Conjugated linoleic acid in canadian dairy and beef products. J Agric Food Chem 1999, 47:1956-1960.

5. Pariza MW, Hargraves WA: A beef-derived mutagenesis modulator inhibits initiation of mouse epidermal tumors by 7,12-dimethylbenz[a]anthracene. Carcinogenesis 1985, 6:591-593.

6. Belury MA: Inhibition of carcinogenesis by conjugated linoleic acid: potential mechanisms of action. J Nutr 2002, 132:2995-2998.

7. McLeod RS, LeBlanc AM, Langille MA, Mitchell PL, Currie DL: Conjugated linoleic acids, atherosclerosis, and hepatic very-low-density lipoprotein metabolism. Am J Clin Nutr 2004, 79:1169S-1174S. 
8. Kritchevsky D, Tepper SA, Wright S, Czarnecki SK, Wilson TA, Nicolosi RJ: Conjugated linoleic acid isomer effects in atherosclerosis: growth and regression of lesions. Lipids 2004, 39:611-616.

9. Lock AL, Parodi PW, Bauman DE: The biology of trans fatty acids: implications for human health and the dairy industry. Australian Journal of Dairy Technology 2005, 60:134-142.

10. O'Shea M, Bassaganya-Riera J, Mohede IC: Immunomodulatory properties of conjugated linoleic acid. Am J Clin Nutr 2004, 79:1199S-1206S.

11. Reynolds CM, Loscher CE, Moloney AP, Roche HM: Cis-9, trans-11 -conjugated linoleic acid but not its precursor trans-vaccenic acid attenuate inflammatory markers in the human colonic epithelial cell line Caco-2. Br J Nutr 2008, 100:13-17.

12. Huot PS, Sarkar B, Ma DW: Conjugated linoleic acid alters caveolae phospholipid fatty acid composition and decreases caveolin-1 expression in MCF-7 breast cancer cells. Nutr Res 2010, 30:179-185.

13. Ma DW, Field CJ, Clandinin MT: An enriched mixture of trans-10, cis-12 -CLA inhibits linoleic acid metabolism and PGE2 synthesis in MDA-MB -231 cells. Nutr Cancer 2002, 44:203-212.

14. Stender S, Astrup A, Dyerberg J: Ruminant and industrially produced trans fatty acids: health aspects. Food Nutr Res 2008, :52.

15. Allison DB, Egan SK, Barraj LM, Caughman C, Infante M, Heimbach JT: Estimated intakes of trans fatty and other fatty acids in the US population. J Am Diet Assoc 1999, 99:166-174.

16. Gebauer SK, Psota TL, Kris-Etherton PM: The diversity of health effects of individual trans fatty acid isomers. Lipids 2007, 42:787-799.

17. Rice BH, Kraft J, Destaillats F, Bauman DE, Lock AL: Ruminant-produced trans-fatty acids raise plasma total and small HDL particle concentrations in male Hartley guinea pigs. J Nutr 2010, 140:2173-2179.

18. Wang Y, Lu J, Ruth MR, Goruk SD, Reaney MJ, Glimm DR, et al: Trans-11 vaccenic acid dietary supplementation induces hypolipidemic effects in JCR:LA-cp rats. J Nutr 2008, 138:2117-2122.

19. Blewett HJ, Gerdung CA, Ruth MR, Proctor SD, Field CJ: Vaccenic acid favourably alters immune function in obese JCR:LA-cp rats. Br J Nutr 2009, 102:526-536.

20. Gebauer SK, Chardigny JM, Jakobsen MU, Lamarche B, Lock AL, Proctor SD, et al: Effects of ruminant trans fatty acids on cardiovascular disease and cancer: a comprehensive review of epidemiological, clinical, and mechanistic studies. Adv Nutr 2011, 2:332-354.

21. Corl BA, Barbano DM, Bauman DE, Ip C: cis-9, trans-11 CLA derived endogenously from trans-11 18:1 reduces cancer risk in rats. J Nutr 2003, 133:2893-2900.

22. Kay JK, Mackle TR, Auldist MJ, Thomson NA, Bauman DE: Endogenous synthesis of cis-9, trans-11 conjugated linoleic acid in dairy cows fed fresh pasture. J Dairy Sci 2004, 87:369-378.

23. Strittmatter P, Spatz L, Corcoran D, Rogers MJ, Setlow B, Redline R: Purification and properties of rat liver microsomal stearyl coenzyme $A$ desaturase. Proc Natl Acad Sci USA 1974, 71:4565-4569.

24. Enoch $\mathrm{HG}$, Catala A, Strittmatter P: Mechanism of rat liver microsomal stearylCoA desaturase. Studies of the substrate specificity, enzyme-substrate interactions, and the function of lipid. J Biol Chem 1976, 251:5095-5103.

25. Flowers MT, Ntambi JM: Role of stearoyl-coenzyme A desaturase in regulating lipid metabolism. Curr Opin Lipidol 2008, 19:248-256.

26. Liu X, Strable MS, Ntambi JM: Stearoyl CoA desaturase 1: role in cellular inflammation and stress. Adv Nutr 2011, 2:15-22.

27. Mercuri O, Peluffo RO, Brenner RR: Effect of insulin on the oxidative desaturation ofa-linolenic, oleic and palmitic acids. Lipids 1967, 2:284-285.

28. Stryjecki C, Roke K, Clarke S, Nielsen D, Badawi A, El-Sohemy A, et al: Enzymatic activity and genetic variation in SCD1 modulate the relationship between fatty acids and inflammation. Mol Genet Metab 2012, 105:421-427.

29. Lee KN, Pariza MW, Ntambi JM: Differential expression of hepatic stearoylCoA desaturase gene 1 in male and female mice. Biochim Biophys Acta 1996, 1304:85-88.

30. Giltay EJ, Gooren LJ, Toorians AW, Katan MB, Zock PL: Docosahexaenoic acid concentrations are higher in women than in men because of estrogenic effects. Am J Clin Nutr 2004, 80:1167-1174.

31. Warensjo E, Ingelsson E, Lundmark P, Lannfelt L, Syvanen AC, Vessby B, et al: Polymorphisms in the SCD1 gene: associations with body fat distribution and insulin sensitivity. Obesity (Silver Spring) 2007, 15:1732-1740.

32. Fontaine-Bisson B, Wolever TM, Connelly PW, Corey PN, El-Sohemy A: NF-kappaB -94Ins/Del ATTG polymorphism modifies the association between dietary polyunsaturated fatty acids and HDL-cholesterol in two distinct populations. Atherosclerosis 2009, 204:465-470.

33. Lee IM, Paffenbarger RS Jr: Physical activity and stroke incidence: the Harvard Alumni Health Study. Stroke 1998, 29:2049-2054.

34. Matthews DR, Connolly AA, Holman RR, Turner RC: Physiology of insulin secretion: problems of quantity and timing. Neth J Med 1985, 28(Suppl 1):20-24.

35. Folch J, LEES M, SLOANE STANLEY GH: A simple method for the isolation and purification of total lipides from animal tissues. J Biol Chem 1957, 226:497-509.

36. Merino DM, Johnston $H$, Clarke S, Roke K, Nielsen D, Badawi A, et al: Polymorphisms in FADS1 and FADS2 alter desaturase activity in young Caucasian and Asian adults. Mol Genet Metab 2011, 103:171-178.

37. Monteiro J, Li FJ, Maclennan M, Rabalski A, Moghadasian MH, Nakamura MT, et al: Menhaden oil, but not safflower or soybean oil, aids in restoring the polyunsaturated fatty acid profile in the novel delta-6-desaturase null mouse. Lipids Health Dis 2012, 11:60.

38. Huang YC, Luedecke LO, Shultz TD: Effect of Cheddar Cheese Consumption on Plasma Conjugated Linoleic-Acid Concentrations in Men. Nutr Res 1994, 14:373-386.

39. Zlatanos SN, Laskaridis K, Sagredos A: Conjugated linoleic acid content of human plasma. Lipids Health Dis 2008, 7:34.

40. Herbel BK, McGuire MK, McGuire MA, Shultz TD: Safflower oil consumption does not increase plasma conjugated linoleic acid concentrations in humans. Am J Clin Nutr 1998, 67:332-337.

41. Iversen SA, Cawood P, Dormandy TL: A Method for the Measurement of A Diene-Conjugated Derivative of Linoleic-Acid, 18-2(9,11), in Serum Phospholipid, and Possible Origins. Ann Clin Biochem 1985, 22:137-140.

42. Nikpartow N, Danyliw AD, Whiting SJ, Lim HJ, Vatanparast H: Beverage consumption patterns of Canadian adults aged 19 to 65 years. Public Health Nutr 2012, 15:2175-2184.

43. Garriguet D: Canadians' eating habits. Health Rep 2007, 18:17-32.

44. Mauvoisin D, Mounier C: Hormonal and nutritional regulation of SCD1 gene expression. Biochimie 2011, 93:78-86.

45. Josse AR, Garcia-Bailo B, Fischer K, El-Sohemy A: Novel effects of hormonal contraceptive use on the plasma proteome. PLoS One 2012, 7:e45162.

46. Baylin A, Kim MK, Donovan-Palmer A, Siles X, Dougherty L, Tocco P, et al: Fasting whole blood as a biomarker of essential fatty acid intake in epidemiologic studies: comparison with adipose tissue and plasma. Am J Epidemiol 2005, 162:373-381.

47. Dilzer A, Park Y: Implication of conjugated linoleic acid (CLA) in human health. Crit Rev Food Sci Nutr 2012, 52:488-513.

doi:10.1186/1743-7075-10-50

Cite this article as: Abdelmagid et al:: Plasma concentration of cis9trans 11 CLA in males and females is influenced by SCD1 genetic variations and hormonal contraceptives: a cross-sectional study. Nutrition \& Metabolism 2013 10:50.

\section{Submit your next manuscript to BioMed Central and take full advantage of:}

- Convenient online submission

- Thorough peer review

- No space constraints or color figure charges

- Immediate publication on acceptance

- Inclusion in PubMed, CAS, Scopus and Google Scholar

- Research which is freely available for redistribution 